\title{
Optimizing Heavy Metals Removal of Excess Sludge by Biodegradable Chelants GLDA Using a Response Surface Methodological Approach
}

\author{
Xu Da-Yong*, Hong Ya-Jun, Yao Qiao-Feng, Cao Pei-Pei, \\ Zhan Ling-Ling, Zhang Ming \\ School of Biochemical Engineering, Anhui Polytechnic University, Wuhu, Anhui, China
}

Received: 24 February 2017

Accepted: 27 September 2017

\begin{abstract}
High heavy metals content is the major drawback of sludge resource, especially for sludge derived from an industrial wastewater treatment plant. A novel and more environmentally friendly kind of chelating agent, GLDA, was employed to treat sludge contaminated by heavy metals in the present study. The effects of the GLDA concentration, $\mathrm{pH}$, and reaction time on sludge heavy metals availability and removal were investigated, and the response surface methodology (RSM) based on the Box-Behnken design was employed to optimize these parameters. The results showed that the higher GLDA concentration and the lower $\mathrm{pH}$ led to the higher removal rate of heavy metals, but the effect of longer reaction time is not obvious. The optimum conditions of extraction reaction at a GLDA concentration of $0.05 \mathrm{~mol} \cdot \mathrm{L}^{-1}, \mathrm{pH}$ of 3.56 , and reaction time of $2.05 \mathrm{~h}$, under the optimum conditions that the comprehensive heavy metals removal rate was $76.40 \%$, and the extraction efficiencies of $\mathrm{Cd}, \mathrm{Cu}, \mathrm{Pb}$, and $\mathrm{Ni}$ can reach $81.04 \%, 77.35 \%, 67.75 \%$, and $75.78 \%$, respectively. Analyzing the response surface plots and contour plots indicated that the effect of $\mathrm{pH}$ was more significant than GLDA concentration and reaction time. Scan electron microscope (SEM) observation demonstrated that the flocculent structure of sludge was replaced obviously by mass structure and the layered structure after treatment. Meanwhile, adsorption ability and volume were reduced. The research results also showed that the GLDA treatment sludge can effectively reduce sludge heavy metals content and improve chemical stability, which is advantageous to the sludge dewatering and its further processing and utilization.
\end{abstract}

Keywords: GLDA, heavy metals, removal rate, response surface methodology, scanning electron microscope

*e-mail: xdy826@ahpu.edu.cn 


\section{Introduction}

Excess sludge is the largest by-product of the wastewater treatment process, creating huge quantities of sludge that need to be disposed of according to the techniques currently employed for wastewater treatment. One of the most potential treatments of sludge is the land application for valuable components recycling, such as nitrogen, phosphorus, and organic matter. However, the problem is that sludge also contain high levels of heavy metals, which is one of the biggest obstacles to sludge land application. Heavy metal is one of the most dangerous materials in contamination sludge, such as copper, chromium, cadmium, lead, and mercury. They are nonbiodegradable and could be stabilized in the environment [1]. When heavy metals enter the human body or other living organisms through drinking water as well as the food chain, they will cause many diseases and allergies, and finally destroy the body [2]. Sludge contaminated with heavy metals also has a serious threat to sustainable development of human health and the environment [3-4]. Therefore, the heavy metals treatment of excess sludge has attracted attention all over the world owing to its high content, toxicity, and risk to the environment [5-7].

There are many methods for heavy metals removal of sludge, such as chemical extraction, electrochemical, ultrasonic, biological, microorganism, and phytoremediation technologies, and these methods can be divided into 3 types: physical, chemical, and biological methods [5], of which chemical extraction is one of the most commonly and widely used methods for heavy metals removal of sludge due to its simple operation and efficiency [8]. The agents used for heavy metals removal include citric acid (CA), Ethylenediaminetetraacetic acid (EDTA), ethylenediaminedisuccinic acid (EDDS), and Fenton. Among these agents, EDTA is used for leaching, repairing, and mobility prediction research of heavy metals in contamination medium frequently, and has been proven to be an effective chelating agent for heavy metals removal. However, it is poorly biodegradable and liable to cause secondary pollution [9]. EDDS is a biological chelating agent with the ability to biodegrade, and can stability chelate with metals [10], but the high cost of the EDDS limits its popularization and application [11]. There are also some drawbacks in Fenton oxidation heavy metals treatment of sludge, including its low optimum reaction $\mathrm{pH}(\mathrm{pH}=2-3)$, high salt condition, and the difficult subsequent processing of sludge [1213]. Therefore, in the selection stage of the agents used for heavy metals removal with chemical extraction, these limitations should be taken into account, and it is imperative to seek a more environmentally friendly agent to replace such ligands.

Recently, a novel and more environmentally friendly kind of chelating agent, tetrasodium of $\mathrm{N}$, N-bis (carboxymethyl) glutamic acid (GLDA), has been introduced and has garnered the attention of researchers [14]. GLDA is a biodegradable chelant made from plant materials based on the green chemistry process
[15-16]. Compared to EDTA, GLDA exhibits similar ability and efficiency for heavy metals treatment [17], GLDA as a washing chelator for the heavy metals treatment of contaminated soil and dry sludge has been reported by Wu et al. [18] and Wang et al. [19], and results of Wu showed that GLDA could remove more than $80 \%$ of $\mathrm{Cd}, \mathrm{Ni}$, and $\mathrm{Cu}$ of dry sludge. However, there are few studies on the utilization of GLDA as a chelating reagent to remove heavy metals from industrial sludge before dewatering, it is well-known that sludge contains lots of water and dewatering of the sludge is a big challenge for its volume reduction and transportation and disposal cost savings. Thus, in this study, GLDA is expected to improve sludge dewatering performance and to achieve the heavy metals removal at the same time, which is the key point conducive to popularization and application of the GLDA utilization in heavy metals treatment of sludge before dewatering. Additionally, in order to consider the interaction effects between the extraction factors of the sludge treatment with GLDA, the response surface methodology (RSM) [20-21], a useful experimental design and analysis tool, was employed to obtain the optimum reaction conditions. Pioneer works have proven that RSM as a powerful statistical tool could optimize the process parameters and be used for experiment design, model building, evaluating the effects of several factors, and reduce the number of experiments.

The objectives of this work were:

1) Evaluate the heavy metals removal effect from excess sludge before dewatering using an environmentally friendly chelating reagent GLDA.

2) Optimize extraction factors, including GLDA concentration, $\mathrm{pH}$, and contact time to achieve the highest removal of heavy metals.

3) Investigate heavy metals distribution of the sludge sample before and after under the optimization extraction conditions with the aid of GLDA using the BCR sequential extraction procedure.

4) Moreover, the apparent morphologies of the raw and treated sludge were also described using scanning electron microscopy (SEM) in order to evaluate sludge dewatering performance and the heavy metals removal effect.

\section{Materials and Methods}

\section{Excess Sludge and Chemical Agents}

The excess sludge used for the extraction experiment in this study was collected from a secondary sedimentation tank of industrial wastewater treatment station of Chery Automobile Co., Ltd., (Wuhu, China). The characteristics of the raw sludge are shown in Table 1.

The chemical agents included $\mathrm{H}_{2} \mathrm{SO}_{4}(98 \%), \mathrm{HClO}_{4}$ (70-72\%), $\mathrm{HCl}(36-38 \%), \mathrm{HNO}_{3}(65-68 \%), \mathrm{CH}_{3} \mathrm{COOH}$ $\left(0.11 \mathrm{~mol} \cdot \mathrm{L}^{-1}\right), \mathrm{NH}_{2} \mathrm{OH} \cdot \mathrm{HCl}\left(0.1 \mathrm{~mol} \cdot \mathrm{L}^{-1}, \mathrm{pH}=2\right), \mathrm{H}_{2} \mathrm{O}_{2}$ (30\%), $\mathrm{NH}_{4} \mathrm{OAc}\left(1 \mathrm{~mol} \cdot \mathrm{L}^{-1}\right)$, and GLDA $(40 \%$ of water solution) - all purchased from Hao Rui Chemical Co., Ltd. 
Table 1, Characteristics of initial sludge.

\begin{tabular}{|c|c|c|c|c|c|c|c|}
\hline \multirow{2}{*}{$\begin{array}{c}\text { Water } \\
\text { content } \\
(\%)\end{array}$} & $\mathrm{pH}$ & \multicolumn{5}{|c|}{ Concentrations of heavy metals* } \\
\cline { 3 - 8 } & & Heavy metals & $\begin{array}{c}\text { Concentrations of heavy met- } \\
\text { als }\left(\mathrm{mg} \cdot \mathrm{kg}^{-1}\right)\end{array}$ & $\begin{array}{c}\text { Acid-soluble } \\
(\%)\end{array}$ & $\begin{array}{c}\text { Reducible } \\
(\%)\end{array}$ & Oxidizable (\%) & Residual (\%) \\
\hline \multirow{3}{*}{96.23} & \multirow{3}{*}{8.35} & 40.3 & 31.01 & 19.55 & 23.31 & 26.14 \\
\cline { 3 - 9 } & & $\mathrm{Cd}$ & 46.3 & 22.50 & 11.62 & 22.32 & 43.57 \\
\cline { 3 - 9 } & & $\mathrm{Pb}$ & 164.42 & 19.18 & 16.02 & 13.87 & 50.93 \\
\cline { 3 - 9 } & $\mathrm{Ni}$ & 2435.42 & 30.04 & 26.40 & 22.13 & 21.44 \\
\hline
\end{tabular}

*After being dewatered and dried at $105^{\circ} \mathrm{C}$ for 24 hours of raw sludge

(Shanghai). All chemicals were analytical grade agents and distilled water was used for solution preparation.

\section{Single-Factor Experiments}

The single factor experiments were carried out in a beaker flask to investigate the effects of GLDA concentration $(\mathrm{C}=0.01,0.02,0.03,0.04,0.05$, $\left.0.06 \mathrm{~mol} \cdot \mathrm{L}^{-1}\right)$, contact time $(\mathrm{T}=1,2,3,4,5,6 \mathrm{~h})$, and $\mathrm{pH}\left(\mathrm{pH}=3,4,5,6,7,8\right.$, adjusted with $\left.\mathrm{HNO}_{3}\right)$ on the $\mathrm{Cd}$, $\mathrm{Cu}, \mathrm{Pb}$, and $\mathrm{Ni}$ removal of sludge before dewatering.

Batch extraction experiments were conducted in aqueous suspension systems. For each run we prepared $250 \mathrm{ml}$ beaker flasks and put $200 \mathrm{~mL}$ raw sludge into each. For the GLDA concentration effect investigation, first we added GLDA solution to adjust the concentration to $0.01,0.02,0.03,0.04,0.05$, and we $0.06 \mathrm{~mol} \cdot \mathrm{L}^{-1}$, respectively. At the same time, we fixed the reaction time at $1 \mathrm{~h}$ and did not adjust $\mathrm{pH}$ of the solution. Then the suspensions were processed at $250 \mathrm{rpm}$ for $60 \mathrm{~min}$ at $20^{\circ} \mathrm{C}$. Last, the reaction solution was filtered through a $0.45 \mu \mathrm{m}$ membrane filter and the filtrate and the solid sludge were properly pretreated for analysis. Based on the optimum GLDA concentration determined, we adjusted the $\mathrm{pH}$ values of suspension systems for $3,4,5,6,7$, and 8 using $\mathrm{HNO}_{3}$, and set contact times of $1,2,3,4,5$, and 6 $\mathrm{h}$, and reacted of the suspension systems under the same conditions in order to investigate the effects of $\mathrm{pH}$ and contact time on metals removal. Meanwhile, we took the GLDA-free raw sludge as the control.

\section{Experimental Design of RSM}

A RSM approach based on Box-Behnken design (BBD) was employed to optimize the extraction factors for heavy metals removal of sludge, and three factors GLDA concentration, $\mathrm{pH}$ and contact time were selected for designing the experiment that marked as coded $\mathrm{X}_{1}$, $\mathrm{X}_{2}, \mathrm{X}_{3}$, which represent the independent factors of low, medium, and high levels. Take the comprehensive heavy metals removal rate (Y) as the response value, and the ranges and levels of independent factors of this experiment are shown in Table 2. There are a total of 17 experiments, with 12 experiments for factorial design and 5 experiments for replication of the central point.

\section{Analytical Methods}

Both the raw sludge and the reaction suspensions after experiment were filtered through a $0.45 \mu \mathrm{m}$ membrane filter, then the filtrate was properly stored at $4^{\circ} \mathrm{C}$ and the solid sludge was dried by oven at $105^{\circ} \mathrm{C}$ for $24 \mathrm{~h}$, ground, and sieved by $180 \mu \mathrm{m}$ prior to analysis. The $\mathrm{pH}$ value of the raw sludge and the reaction suspensions was determined by a digital $\mathrm{pH}$ meter (6010M, Shanghai, China). The sludge samples were digested successively with the aid of the aqua regain and perchloric acid solution at $185^{\circ} \mathrm{C}$ and $205^{\circ} \mathrm{C}$ for 3 and 7 hours. The concentrations of the heavy metals in the filtrate and digestion solutions were measured by atomic absorption method (TAS-990, Beijing Purkinje General Instrument Co., Ltd.). The species distribution of heavy metals of the sludge sample before and after the experiment with GLDA were analyzed using the modified BCR sequential extraction procedure [22-23], there are four species following each extraction step, such as acid-soluble, reducible, oxidizable, and residual heavy metals that could be extracted, respectively. Additionally, the microstructure characterization of the sludge sample before and after experiment with GLDA was also analyzed using the scanning electron microscope (SEM) (Hitachi S-4800, Japan) method.

In this work, RSM and predictive polynomial quadratic equation were employed in order to determine the optimum extraction conditions. Sludge comprehensive heavy metals removal rate (Y) was introduced as the response value for the curve, and the shape and the contour of the response surface were analyzed. The value of $\mathrm{Y}$ was based on the toxic metals $\mathrm{Cd}, \mathrm{Cu}, \mathrm{Pb}$, and $\mathrm{Ni}$ on the environment [24], which according to the analytic hierarchy process (AHP) [25-26] for coefficient

Table 2. Levels and codes of Box-Behnken design.

\begin{tabular}{|c|c|c|c|c|}
\hline \multirow{2}{*}{ Factor } & Code & \multicolumn{3}{|c|}{ Level } \\
\cline { 3 - 5 } & -1 & 0 & +1 \\
\hline \multirow{2}{c}{$\begin{array}{c}\mathrm{c} \mathrm{mol} \cdot \mathrm{L}^{-1} \\
\mathrm{pH} \\
\mathrm{Time} / \mathrm{h}\end{array}$} & $\mathrm{X}_{1}$ & 0.04 & 0.05 & 0.06 \\
\cline { 2 - 5 } & $\mathrm{X}_{2}$ & 3 & 4 & 5 \\
\cline { 2 - 5 } & $\mathrm{X}_{3}$ & 1 & 2 & 3 \\
\hline
\end{tabular}




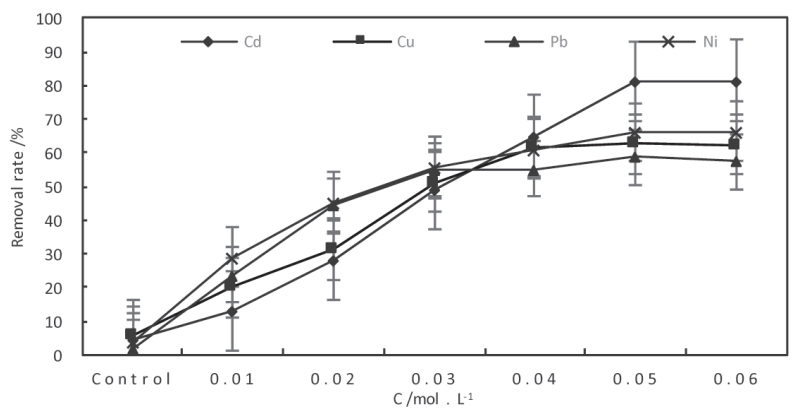

Fig. 1. Effect of GLDA concentrations on heavy metals removal rate.

determine. So, the value of $\mathrm{Y}$ was equal to the removal rates of $\mathrm{Cd}, \mathrm{Cu}, \mathrm{Pb}$, and Ni multiplied by $0.3,0.2,0.3$, and 0.2 , respectively.

\section{Results and Discussion}

\section{Effect of GLDA Concentration}

Agents' concentration is one of the important factors affecting the removal efficiency of heavy metals in sediment [27]. In order to examine the effect of GLDA concentration on the removal rate of heavy metals, six concentrations were tested in this study from 0.01 to $0.06 \mathrm{~mol} \cdot \mathrm{L}^{-1}$ under the same contact time $(1 \mathrm{~h})$, and did not adjust $\mathrm{pH}$ of the solution. The result showed as in Fig. 1.

It can be observed that the removal rates of $\mathrm{Cd}, \mathrm{Cu}$, $\mathrm{Pb}$, and $\mathrm{Ni}$ were all increased with the increase of GLDA concentration (Fig. 1), which showing a trend of significant rise first and then stabilized in the end. The highest removal rates of $\mathrm{Cd}, \mathrm{Cu}, \mathrm{Pb}$, and $\mathrm{Ni}$ were at a GLDA of $0.05 \mathrm{~mol} \cdot \mathrm{L}^{-1}$, which were $81.20 \%, 62.50 \%, 58.76 \%$, and $66.03 \%$, respectively. At the same time, the contents of heavy metals in sludge were decreased from $40.3,46.3$, 164.42 , and $2,435.32 \mathrm{mg} \cdot \mathrm{kg}^{-1}$ to $7.58,17.36,67.81$, and $827.31 \mathrm{mg} \cdot \mathrm{kg}^{-1}$, respectively. Meanwhile, the heavy metals contents in suspensions supernatant were analyzed in order to determine the metals transfer from solid phase to liquid phase of sludge under GLDA extraction, results showing that the contents of $\mathrm{Cd}, \mathrm{Cu}, \mathrm{Pb}$, and $\mathrm{Ni}$ increased obviously in the supernatant, and they increased from $0.049,0.012,0.164$, and $2 \mathrm{~g} \cdot \mathrm{mL}^{-1}$ to $0.089,0.0195,0.2604$, and $3.3206 \mathrm{~g} \cdot \mathrm{mL}^{-1}$, respectively. The reason for this result was that a higher concentration of chelating agent could bind to more heavy metals ions, which promoted metals ion-ligand complexing reaction transferring to the chelate formation process and increased removal efficiency [17-18]. However, co-solubilization effects between the target heavy metals and co-existing metals such as $\mathrm{Ca}$, $\mathrm{Mg}, \mathrm{Fe}$, and $\mathrm{Al}$ might result in reducing removal efficiency [19]. In addition, the removal efficiency of the four kinds of metals under GLDA treatment was ordered as follow $\mathrm{Cd}>\mathrm{Ni}>\mathrm{Cu}>\mathrm{Pb}$.

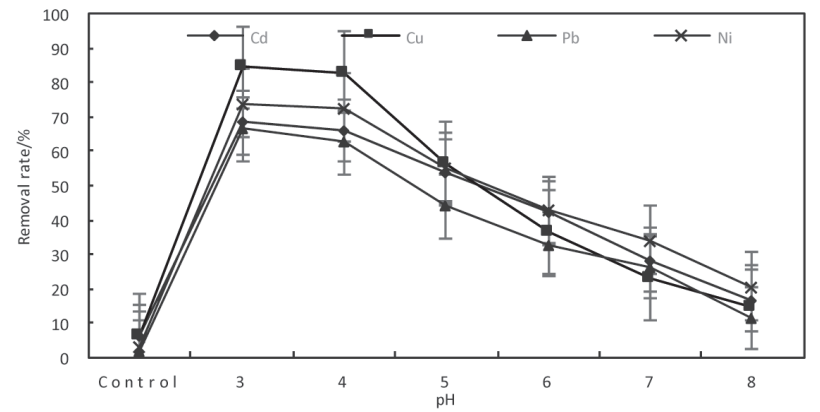

Fig. 2. Effect of $\mathrm{pH}$ on heavy metals removal rate.

\section{Effect of $\mathrm{pH}$}

In general, acidic condition is beneficial for heavy metals removal and the removal efficiency significantly decreased with the increasing $\mathrm{pH}$. In other words, the heavy metals are easy to depose and became difficult to be removed when the condition in alkaline by regulating the metals chelant stability constants, ion-exchange, the sorption or desorption reactions a nd the aqueous metals fractions [28]. However, an overly acidic or alkaline condition is not good for the subsequent processing of sludge. So, in this work the value of $\mathrm{pH}$ was discussed among $3,4,5,6,7$, and 8 to investigate $\mathrm{pH}$ effects on metals removal, and the results follow as Fig. 2.

The removal rate of heavy metals gradually decreased, with $\mathrm{pH}$ increasing from 3 to 8 (Fig. 2). The highest removal efficiencies for $\mathrm{Cd}, \mathrm{Cu}, \mathrm{Pb}$, and $\mathrm{Ni}$ were achieved at $\mathrm{pH} 3: 68.42 \%, 84.51 \%, 66.52 \%$, and $74.05 \%$, respectively. Meanwhile, the heavy metals contents in the sludge dropped to $12.37,7.17,55.05$, and $632 \mathrm{mg} \cdot \mathrm{kg}^{-1}$. The minimum removal rates for $\mathrm{Cd}, \mathrm{Cu}, \mathrm{Pb}$, and $\mathrm{Ni}$ were $16.51 \%, 14.51 \%, 11.41 \%$, and $16.51 \%$, respectively, when $\mathrm{pH}$ increased to 8 . This result was similar to the study conducted by $\mathrm{Wu}$ et al. [18], which showed that the extraction efficiency of heavy metals was best achieve at $\mathrm{pH}$ 3. Heavy metals removal efficiency influenced by the intensity of the solution of proton movement, the proton intensity increasing at the right area of the acid, then the heavy metals removal effect was obvious. On the other hand, heavy metals ion precipitation reaction can also affect removal efficiency when the $\mathrm{pH}$ value increased to alkali [29].

\section{Effect of Contact Time}

Pioneer [23] research showed that $24 \mathrm{~h}$ was the optimum reaction time of extraction reaction for metals removal of dry sludge. In order to analyze the effect of the contact time on heavy metals removal efficiency of sludge before dewatering, experiments of different reaction time $(1,2,3,4,5$, and $6 \mathrm{~h})$ were conducted in this study, the results follow as in Fig. 3. It can be seen from Fig. 3 that, compared to the control group, the sludge before dewatering extraction for $2 \mathrm{~h}$ by GLDA that the removal rates of $\mathrm{Cd}, \mathrm{Cu}, \mathrm{Pb}$, and $\mathrm{Ni}$ increased from 


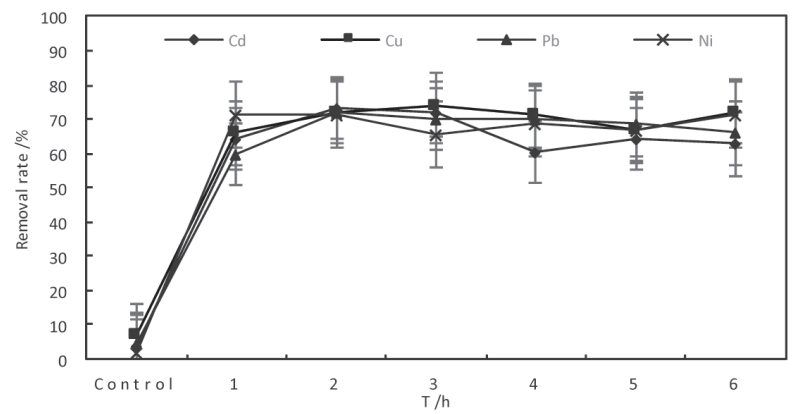

Fig. 3. Effect of contact time on heavy metals removal rate.

$3.70 \%, 6.87 \%, 4.50 \%$, and $1.73 \%$ to $73.28 \%, 72.21 \%$, $71.98 \%$, and $71.22 \%$, respectively. Meanwhile, heavy metals content of the corresponding decreased to 10.77 , $12.87,46.07$, and $700.91 \mathrm{mg} \cdot \mathrm{kg}^{-1}$ in sludge solid phase. After that, the removal rate of each heavy metal reached a stable state and didn't increase with the increasing contact time. The reason for the results was that the chelation was saturated gradually with the heavy metals desorption and dissolving reaction when the completion of basic chelation late into the sludge matrix after the optimum contact time [30]. Normally, with time increasing, the more closely combined with the sludge of heavy metals are released slowly and finally reached a state of balance [15].

\section{Optimizing $\mathrm{Cd}, \mathrm{Cu}, \mathrm{Pb}$, and $\mathrm{Ni}$ Removal Using RSM}

\section{Model Fitting and Analysis of Variance}

Experiments for heavy metals removal using GLDA extraction and with different combinations of selected factors were conducted in this work, and the results of all 17 tests are summarized in Table 3. To evaluate the influences of GLDA concentration, $\mathrm{pH}$ value, and contact time on removal rate, the design matrix of experimental conditions with the corresponding $\mathrm{Y}$ value in Table 3 were subjected to regression analysis, and the general form of the predictive polynomial quadratic equation is as follows (1):

$$
\begin{gathered}
\mathrm{Y}=75.14+1.95 \mathrm{X}_{1}-5.26 \mathrm{X}_{2}+1.26 \mathrm{X}_{3} \\
+2.05 \mathrm{X}_{1} \mathrm{X}_{2}+1.65 \mathrm{X}_{1} \mathrm{X}_{3}+0.37 \mathrm{X}_{2} \mathrm{X}_{3} \\
-8.83 \mathrm{X}_{1}{ }^{2}-5.79 \mathrm{X}_{2}{ }^{2}-11.34 \mathrm{X}_{3}{ }^{2}
\end{gathered}
$$

Analysis of variables for a polynomial quadratic equation and test of significance for regression coefficients are completed, and the results follow in Table 4. The F value of the model was 23.25, and Prob $>$ $\mathrm{F}=0.0002$ (if $\mathrm{p}<0.05$, suggests the model is significance [31]), lack of fit is not significant $(\mathrm{P}$ value $=0.4540>$

\begin{tabular}{|c|c|c|c|c|c|c|c|}
\hline \multirow{2}{*}{ Run } & \multicolumn{3}{|c|}{ Level } & \multicolumn{2}{|c|}{$Y(\%)$} & \multirow{2}{*}{$\begin{array}{l}\text { Absolute } \\
\text { error }\end{array}$} & \multirow{2}{*}{$\begin{array}{c}\text { Relative error } \\
(\% .)\end{array}$} \\
\hline & $\mathrm{X}_{1}$ & $\mathrm{X}_{2}$ & $X_{3}$ & True & Predict & & \\
\hline 1 & 0 & 0 & 0 & 76.171 & 75.14 & 1.031 & 0.014 \\
\hline 2 & 1 & 0 & 1 & 60.706 & 59.83 & 0.876 & 0.014 \\
\hline 3 & 0 & 1 & -1 & 50.645 & 51.12 & -0.475 & -0.009 \\
\hline 4 & 0 & -1 & -1 & 64.627 & 62.38 & 2.247 & 0.035 \\
\hline 5 & 0 & 0 & 0 & 76.582 & 75.14 & 1.442 & 0.019 \\
\hline 6 & 1 & -1 & 0 & 64.346 & 65.68 & -1.334 & -0.021 \\
\hline 7 & -1 & 0 & 1 & 53.528 & 52.63 & 0.898 & 0.017 \\
\hline 8 & 0 & 1 & 1 & 52.127 & 54.38 & -2.253 & -0.043 \\
\hline 9 & 0 & -1 & 1 & 64.645 & 64.16 & 0.485 & 0.008 \\
\hline 10 & 0 & 0 & 0 & 75.654 & 75.14 & 0.514 & 0.007 \\
\hline 11 & -1 & 1 & 0 & 52.6 & 51.26 & 1.34 & 0.025 \\
\hline 12 & 1 & 0 & -1 & 53.104 & 54.01 & -0.906 & -0.017 \\
\hline 13 & -1 & -1 & 0 & 64.507 & 65.88 & -1.373 & -0.021 \\
\hline 14 & 0 & 0 & 0 & 76.682 & 75.14 & 1.542 & 0.020 \\
\hline 15 & 0 & 0 & 0 & 70.626 & 75.14 & -4.514 & -0.064 \\
\hline 16 & -1 & 0 & -1 & 52.538 & 53.41 & -0.872 & -0.017 \\
\hline 17 & 1 & 1 & 0 & 60.638 & 59.26 & 1.378 & 0.023 \\
\hline
\end{tabular}
0.05 ), which showed that the model reached the level of

Table 3. Box-Behnken design arrangement and experimental results. 
Table 4. Analysis of variables for regression equation and test of significance for regression coefficients.

\begin{tabular}{|c|c|c|c|c|c|c|}
\hline Source & Sum of squares & $\mathrm{df}$ & Mean Square & F Value & $\begin{array}{l}\text { p-value } \\
\text { Prob }>\text { F }\end{array}$ & Significant \\
\hline Model & 1412.48 & 9 & 156.94 & 23.25 & 0.0002 & $* *$ \\
\hline $\mathrm{X}_{1}$ & 30.5 & 1 & 30.5 & 4.52 & 0.0711 & \\
\hline $\mathrm{X}_{2}$ & 221.71 & 1 & 221.71 & 32.84 & 0.0007 & $* *$ \\
\hline $\mathrm{X}_{3}$ & 12.73 & 1 & 12.73 & 1.89 & 0.2121 & \\
\hline $\mathrm{X}_{1} \mathrm{X}_{2}$ & 16.81 & 1 & 16.81 & 2.49 & 0.1586 & \\
\hline $\mathrm{X}_{1} \mathrm{X}_{3}$ & 10.93 & 1 & 10.93 & 1.62 & 0.2439 & \\
\hline $\mathrm{X}_{2} \mathrm{X}_{3}$ & 0.54 & 1 & 0.54 & 0.079 & 0.7863 & \\
\hline $\mathrm{X}_{1}^{2}$ & 328.37 & 1 & 328.37 & 48.64 & 0.0002 & $* *$ \\
\hline $\mathrm{X}_{2}^{2}$ & 141.11 & 1 & 141.11 & 20.9 & 0.0026 & $* *$ \\
\hline $\mathrm{X}_{3}{ }^{2}$ & 541.73 & 1 & 541.73 & 80.24 & $<0.0001$ & $* *$ \\
\hline Residual & 47.26 & 7 & 6.75 & & & \\
\hline Lack of Fit & 21.1 & 3 & 7.03 & 1.08 & 0.454 & Not \\
\hline Pure Error & 26.16 & 4 & 6.540 & & & \\
\hline Cor Total & 1459.74 & 16 & & & & \\
\hline
\end{tabular}

Notes: $\mathrm{P}<0.05$, significant, sign“*”; $\mathrm{P}<0.01$, very significant, sign“**”, $\mathrm{R}^{2}=0.9676, \mathrm{R}_{\mathrm{Adj}}^{2}=0.9260$

significance with the correlation coefficient of a 0.9676 . The results also indicated that the model in the study of the whole fitting regression area was good, which can explain a $96.76 \%$ change in the response value [32]. $\mathrm{R}_{\text {Adj }}{ }^{2}-\mathrm{R}_{\text {Pred }}{ }^{2}=0.9260-0.7407=0.1853<0.2, \mathrm{CV}=4.13 \%$ $<10 \%$ indicates that the reliability and precision of the experiment were good and high enough. Accuracy of the model was assessed through "adequate precision," which measured the signal-to-noise ratio, and if a ratio is greater than 4 is desirable for more accuracy. The ratio of this model was 12.055 , indicating an adequate signal. The result showed that this model can be used to navigate the design space, and provides an adequate signal to present the truth of the model [33].
The significance test of regression model coefficient (Table 4) reflects that $X_{2}$ and quadratic terms $X_{1}^{2}, X_{2}^{2}$, and $\mathrm{X}_{3}^{2}$ were very significant for heavy metals removal. At the same time, the impact on $\mathrm{Y}$ of $\mathrm{F}$ value from high to low the order was $\mathrm{X}_{2}, \mathrm{X}_{1}$, and $\mathrm{X}_{3}$, and the influence of the interaction item followed as $\mathrm{X}_{1} \mathrm{X}_{2}, \mathrm{X}_{1} \mathrm{X}_{3}$, and $\mathrm{X}_{2} \mathrm{X}_{3}$, whereas the impact of the quadratic items followed as $\mathrm{X}_{3}^{2}, \mathrm{X}_{1}^{2}$, and $\mathrm{X}_{2}^{2}$. Integrated multiple parameters showed that the model was reasonable and reliable, and the relationship between the independent and dependent variables was also reasonable. All these results indicated that the regression model could be used to optimize the removal rate of heavy metals.
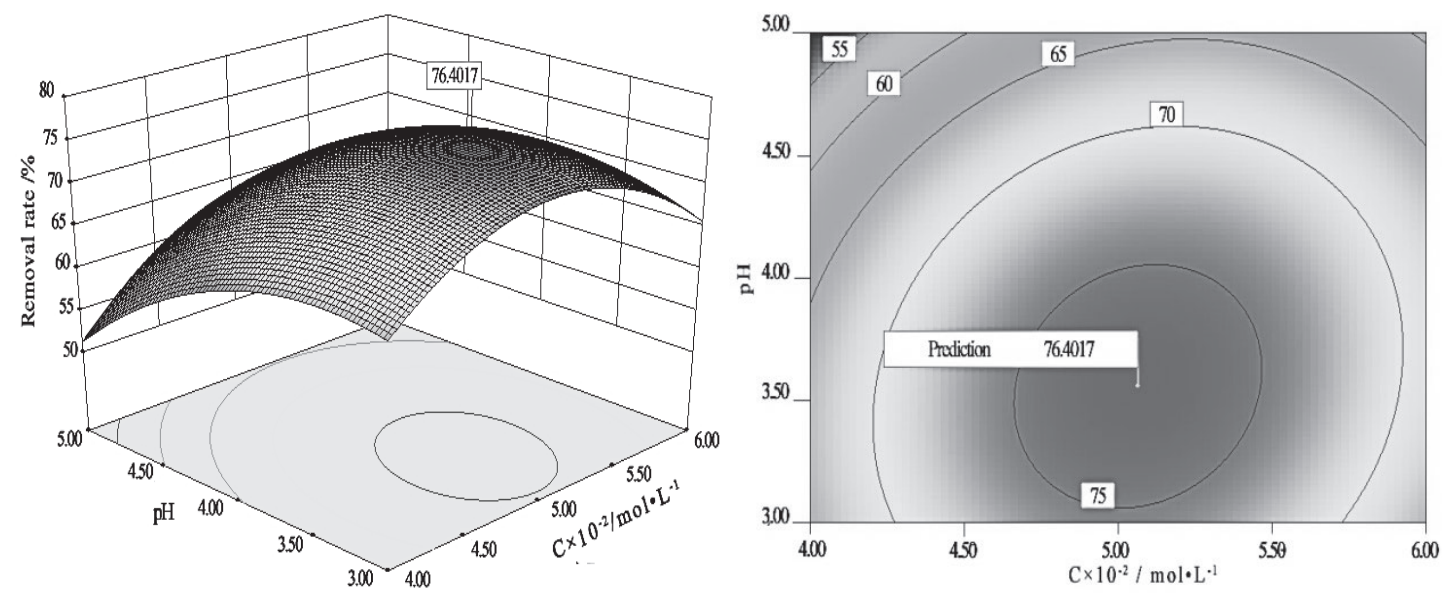

Fig. 4. Effects of $\mathrm{C}$ and $\mathrm{pH}$ on removal rate in response to surface and contour plots. 

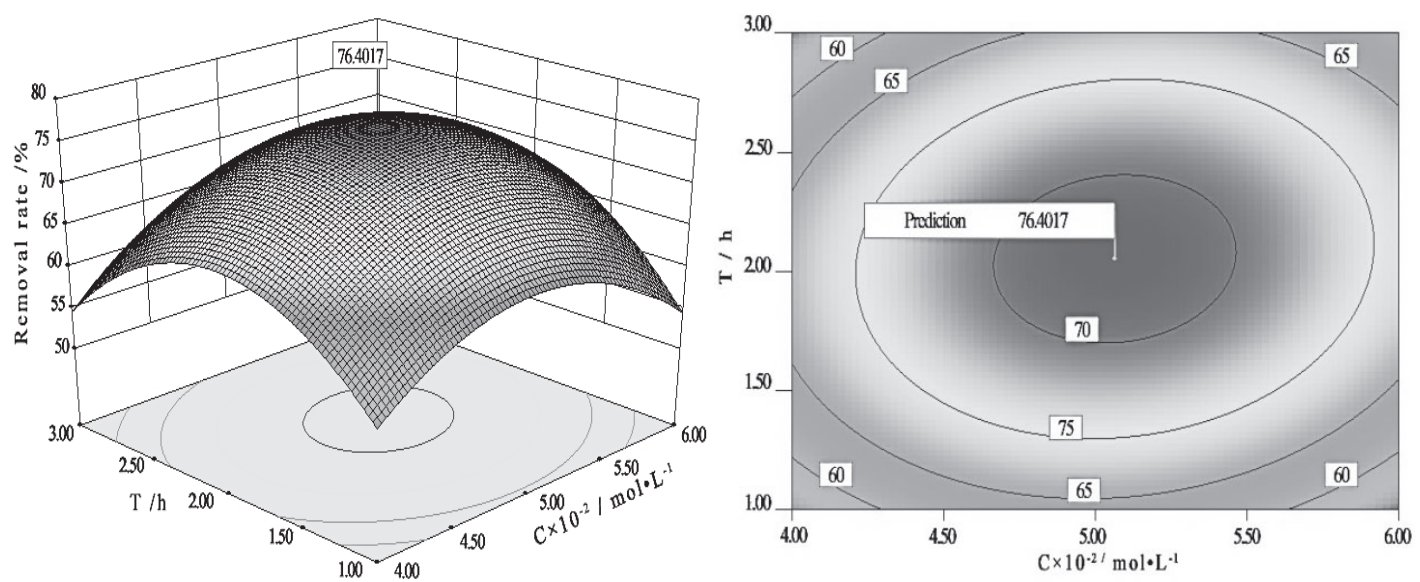

Fig. 5. Effects of $\mathrm{C}$ and $\mathrm{T}$ on removal rate in response surface plots and contour plots.

\section{Analyzing RSM and Determining Optimization Factors}

Following the RSM plots and its corresponding contour lines, the experimental factors interact on the removal rate of heavy metals composite, and the scope of the optimal levels of various factors can be evaluated and determined. The response surface figure reflects the shape of the response surface, and shows that the greater the interaction, the larger the curvature of surface between the factors [34]. Contour shape reflects the strength of the interaction effect of various factors: if the contour plot is oval, it indicates that the interaction between two factors is significant; otherwise, there is no significant interaction when the contour plots are circular [35].

The three-dimensional response surfaces plots and two-dimensional contour lines in Figs 4-6 were based on Eq. (1) with one variable kept constant at its optimum level and varying the other two variables within the experimental range. Fig. 4 was the interaction of GLDA concentration and $\mathrm{pH}$ on heavy metals removal efficiency of sludge at the medium value of reaction time of $2 \mathrm{~h}$, of which the removal rate decreased with $\mathrm{pH}$ increasing at the low level of GLDA concentration. The value of $\mathrm{Y}$ reached minimum at $\mathrm{pH}$ 5. Meanwhile, heavy metals removal rate was promoted first and then decreased with the concentration of GLDA increasing. The removal rate of heavy metals was improved with the GLDA concentration rising until it was over $0.05 \mathrm{~mol} \cdot \mathrm{L}^{-1}$. Combined with the contour, the change of $\mathrm{pH}$ value showed a significant effect on the heavy metals removal rate. Therefore, under the conditions of low $\mathrm{pH}$ and proper reaction time it could improve the removal rate of heavy metals.

The interaction of GLDA concentration and contact time on metals removal at the medium value of $\mathrm{pH}$ is presented in Fig. 5, which shows that the trend of heavy metals removal rate increased with reaction time increasing at the first, and then decreased when GLDA concentration was at a low level. And with increasing the dosage of the GLDA, heavy metals removal rate increased slowly, then stayed stable and decreased slightly in the end. This may be due to the chemical bonds breaking of sludge suspensions when the chelating agent concentration and contact time increased [36]. Consistent with the variance analysis results, the impact of GLDA concentration on heavy metals removal rate

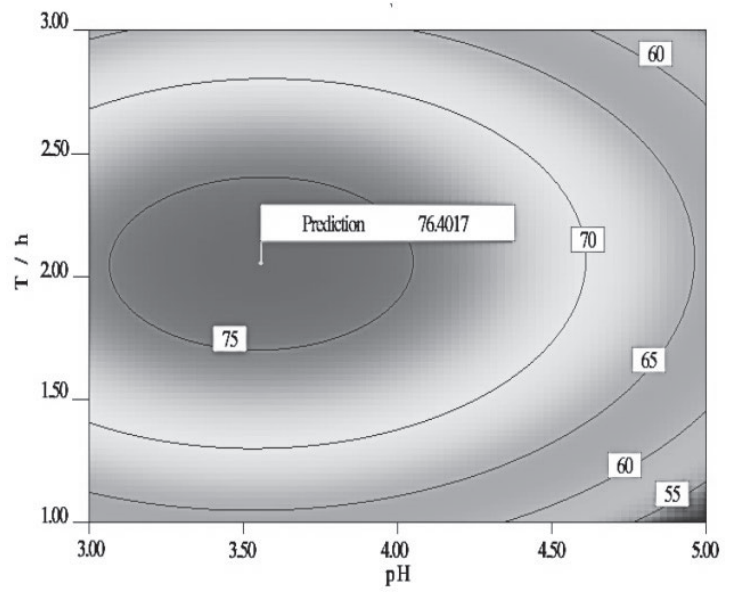

Fig. 6. Effects of $\mathrm{pH}$ and $\mathrm{T}$ on removal rate in response surface plots and contour plots. 
was more significant than reaction time, according to the contour lines.

Fig. 6 revealed that at the medium value of GLDA concentration, the interaction of $\mathrm{pH}$ and reaction time on removal efficiency of heavy metals. It can be seen from Fig. 6 that when $\mathrm{pH}$ value was at a low level, heavy metals removal rate increased slowly with the reaction time increasing and then decreasing. However, the heavy metals removal rate was decreased at a higher $\mathrm{pH}$ value. Combined with the contour, the change of $\mathrm{pH}$ value showed a significant effect on the heavy metals removal rate. Therefore, under conditions of low $\mathrm{pH}$ and proper long reaction time we could improve the removal rate of heavy metals.

According the experiment data, the optimum conditions of Y maximization, which can be calculated by setting the partial derivatives of Eq. (1) to zero with respect to the corresponding variables, was a GLDA of $0.05 \mathrm{~mol} \cdot \mathrm{L}^{-1}$, a $\mathrm{pH}$ of 3.56 , and a reaction time of 2.05 $\mathrm{h}$. The maximum response value for $\mathrm{Y}$ was estimated as $76.40 \%$, and another three confirmation experiments were used to verify the removal rate of heavy metals, of which the results were $75.26 \%, 75.78 \%$, and $77.35 \%$, respectively. Average value of removal efficiency was $76.13 \%$ and had $0.35 \%$ relative error between the prediction value. The result indicated that the model has a good prediction effect on the removal rates of $\mathrm{Cd}, \mathrm{Cu}, \mathrm{Pb}$, and $\mathrm{Ni}$, which were $81.04 \%, 77.35 \%, 67.75 \%$, and $75.78 \%$, respectively. Meanwhile, the $\mathrm{Cd}, \mathrm{Cu}, \mathrm{Pb}$, and $\mathrm{Ni}$ content in sludge was reduced to $7.64,10.49,53.03$, and 589.86 $\mathrm{mg} \cdot \mathrm{kg}^{-1}$, and the corresponding content in supernatant increased from $0.048,0.032,0.347$, and $0.316 \mathrm{~g} \cdot \mathrm{mL}^{-1}$ to $0.373,0.414,3.014$, and $22.155 \mathrm{~g} \cdot \mathrm{mL}^{-1}$, respectively.

\section{Analyzing the Fractions Distribution of Heavy Metals}

We can see from the results of RSM that the removal efficiencies of four kinds of heavy metals were different even under the same conditions, which may be associated with the formation of heavy metals in sludge [37]. Removal efficiency is largely restricted by fractions distribution of heavy metals, and different fractions lead to different removal rates. In general, acid-soluble metals are unstable and vulnerable to be influenced by the external environment, such as $\mathrm{pH}$ and humidity, and is the most easily absorbed by plant and has a higher biological effectiveness. In other words, it is easy to be removed from the system [38]. Therefore, the higher acid-soluble content leads the higher removal efficiency of metals. Base on this, the distribution of heavy metals fractions in sludge before and after treatment by GLDA were analyzed (Fig. 7).

Metals of sludge in the acid-soluble, reducible, and oxidizable fractions were the most easily extractable. Therefore, after GLDA treatment there was a significant decrease of such fractions of all kinds of metals (Fig. 7), this result was same as the previous research conducted by Wang et al. [19]. Fig. 7 shows that the fractions

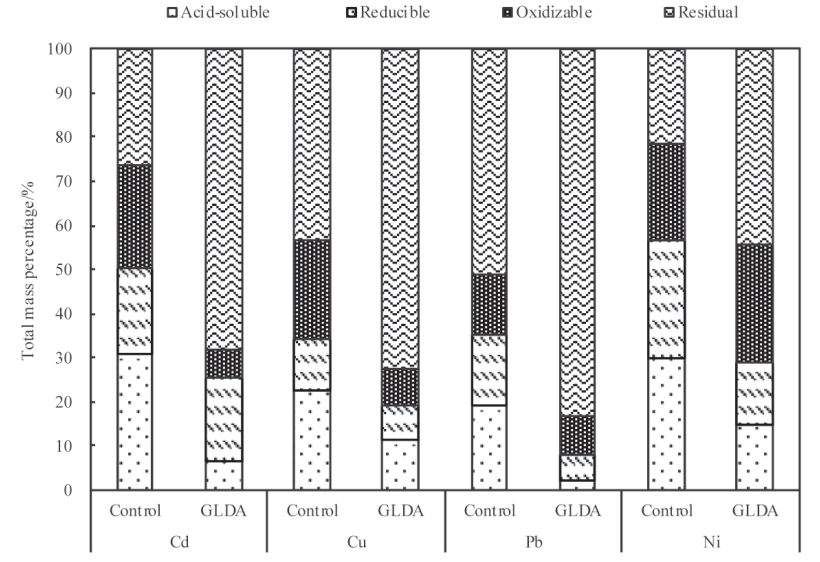

Fig. 7. Fractions distribution of heavy metals in control and GLDA-treated sludge.

distribution of heavy metals changed a lot, especially acid-soluble of $\mathrm{Cd}, \mathrm{Cu}, \mathrm{Pb}$, and $\mathrm{Ni}$ got the removal rate largely, of which $31.01 \%, 22.50 \%, 19.18 \%$, and $30.04 \%$ acid-soluble of $\mathrm{Cd}, \mathrm{Cu}, \mathrm{Pb}$, and $\mathrm{Ni}$ decreased to $6.43 \%$, $11.56 \%, 2.43 \%$, and $14.95 \%$, respectively. Meanwhile, reducible and oxidizable fraction metals also got removal rates that decreased by $0.38 \%, 3.91 \%, 10.31 \%, 12.38 \%$, $16.91 \%, 13.98 \%, 5.44 \%$, and $4.75 \%$, respectively. On the other hand, the residual metals were the most stable fractions of the heavy metals, and the residue state contents of $\mathrm{Cd}, \mathrm{Cu}, \mathrm{Pb}$, and $\mathrm{Ni}$ were $68.01 \%, 72.40 \%$, $83.42 \%$, and $44.16 \%$, respectively. Compared to the other three kinds of heavy metals, the higher residual metals content of $\mathrm{Pb}$ led to lower extraction efficiency.

\section{Analyzing the Apparent Morphology of Sludge}

We used the SEM method to observe and evaluate changes of the morphology and microstructures of the sludge before and after GLDA treatment. Solid samples of the sludge dried at $80^{\circ} \mathrm{C}$ for $24 \mathrm{~h}$, ground into powder, and sprayed gold, and then observed the apparent morphology under $5.0 \mathrm{~mm}$. at $5.0 \mathrm{kv} 8.8 \mathrm{~mm} \cdot 10.0 \mathrm{k}$ ratio condition (Fig. 8).

It can be found that the surface of sludge was dispersed flocculent structure before treatment, and the structure of zoogloea was relatively complete (Fig. 8) [39], which makes the sludge have a larger adsorption capacity and higher water content. It was obvious that the mass structure and layer structure was formed in sludge after GLDA treatment, zoogloea was destructed, sludge dewatering performance was improved, and then heavy metals in the solid phase were released into liquid phase. Meanwhile, the apparent morphology change of the sludge showed that a chelate reaction between GLDA and sludge caused a volume and adsorption capacity of sludge decreasing, which could promote the release of heavy metals and improve the sludge dewatering performance. 
a)

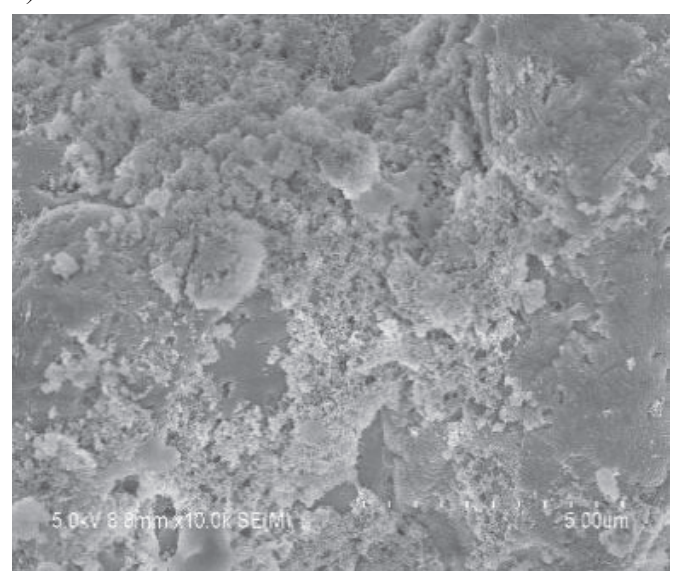

b)

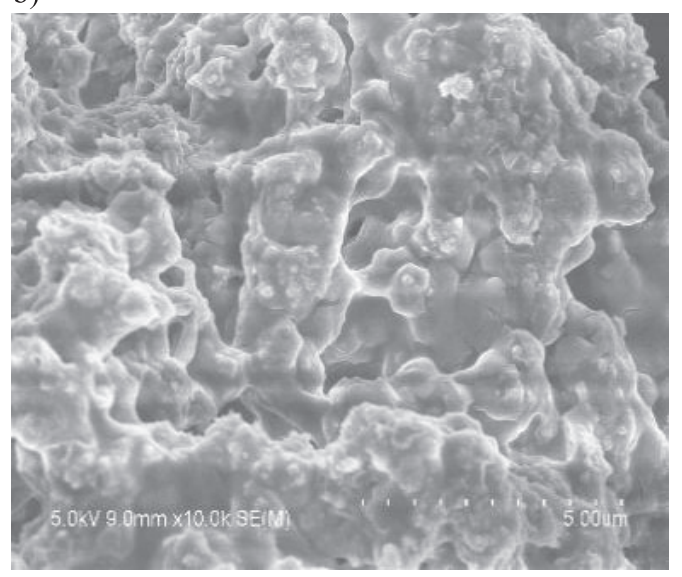

Fig. 8. SEM of sludge before and after GLDA treatment a) raw sludge, b) GLDA treated sludge.

\section{Conclusions}

We investigated chemical extraction of heavy metals from sludge before dewatering using biodegradable chelants GLDA, and the RSM method was used to seek optimal conditions for extraction. Additionally, the distribution of heavy metals and the apparent morphology of the sludge sample before and after treatment under optimized extraction conditions were investigated to evaluate the sludge dewatering performance and the heavy metals removal effect. The single factor experiment results showed that GLDA concentration, $\mathrm{pH}$, and contact time significantly influenced the removal rates of $\mathrm{Cd}$, $\mathrm{Cu}, \mathrm{Pb}$, and $\mathrm{Ni}$, and the highest removal rate of $\mathrm{Cd}, \mathrm{Cu}$, $\mathrm{Pb}$, and $\mathrm{Ni}$ were achieved at a GLDA of $0.05 \mathrm{~mol} \cdot \mathrm{L}^{-1}$, a $\mathrm{pH}$ of 3 , and a contact time of $2 \mathrm{~h}$. According to RSM experiments, the optimum conditions were $76.40 \%$ of the comprehensive heavy metals removal rate at GLDA $0.05 \mathrm{~mol} \cdot \mathrm{L}^{-1}, \mathrm{pH}=3.56$, and reaction time 2.05 $\mathrm{h}$. The results of the confirmation experiments agree with predictions that were $75.26 \%, 75.78 \%$, and $77.35 \%$. The metals fractions distribution and the apparent morphology of the sludge changed a lot after GLDA treatment, which showed that a chelate reaction between GLDA with sludge could promote the release of heavy metals and improve the sludge dewatering performance. The research results also showed that the GLDA treatment sludge can effectively reduce sludge heavy metals content and improve chemical stability, which was advantageous to sludge dewatering and its further processing and utilization.

\section{Acknowledgements}

The authors are grateful for the financial support of the National Natural Science Foundation of China (51408001), Wuhu Science and Technology Plan Projects (2016hm11), the National College Students' Innovative Entrepreneurial Training Program of China (201510363083), and Graduate Students Practice and Innovation Projects of Anhui Polytechnic University in 2016.

\section{References}

1. SHARMA Y.C., SRIVASTAVA V. K., MUKHERJEE A. Synthesis and Application of Nano- $\mathrm{Al}_{2} \mathrm{O}_{3}$ Powder for the Reclamation of Hexavalent Chromium from Aqueous Solutions. J. Chem. Eng. Data. 55 (7), 2390, 2010.

2. DARGAHI, A., GHOLESTANIFAR H., DARVISHI P., BEHZADNIA A. An Investigation and Comparison of Removing Heavy Metals (Lead and Chromium) from Aqueous Solutions Using Magnesium Oxide Nanoparticles. Polish Journal of Environmental Studies. 25 (2), 2016.

3. ADREES M., ALI S., RIZWAN M., ZIA-UR-REHMAN M., IBRAHIM M., ABBAS F., FARID M., QAYYUM M.F., IRSHAD M.K. Mechanisms of silicon-mediated alleviation of heavy metal toxicity in plants: A review. Ecotoxicology Environmental Safety. 119, 186, 2015.

4. AKCIL A., ERUST C., OZDEMIROGLU S., FONTIB V., BEOLCHINI F. A review of approaches and techniques used in aquatic contaminated sediments: metal removal and stabilization by chemical and biotechnological processes. Journal of Cleaner Production. 86, 24, 2015.

5. SHARMA S., SINGH B., and MANCHANDA V.K. Phytoremediation: role of terrestrial plants and aquatic macrophytes in the remediation of radionuclides and heavy metal contaminated soil and water. Environmental Science and Pollution Research. 22 (2), 946, 2015.

6. DOMINGUEZ M.T., ALEGRE J.M., MADEJON P., MADEJON E., BURGOS P., CABRERA F., MARANON T., MURILLO J.M. River banks and channels as hotspots of soil pollution after large-scale remediation of a river basin. Geoderma. 261, 133, 2016.

7. HUBER M., WELKER A., HELMREICH B. Critical review of heavy metal pollution of traffic area runoff: Occurrence, influencing factors, and partitioning. Science of the Total Environment. 541, 895, 2016.

8. YIP T.C.M., YAN D.Y.S., YUI M.M.T., TSANG D.C.W., LO I.M.C. Heavy metal extraction from an artificially contaminated sandy soil under EDDS deficiency: significance of humic acid and chelant mixture. Chemosphere. 80 (4), 416, 2010.

9. KE X., LI P.J., ZHANG Y., SUN T. Heavy metals removal and its kinetics in contaminated soil under effects of EDTA washing. The journal of applied ecology. 18 (3), 601, 2007. 
10. KOWALCZYK M., HUBICKI Z., KOLODYNSKA D. Removal of heavy metal ions in the presence of the biodegradable complexing agent of EDDS from waters. Chemical Engineering Journal. 221 (2), 512, 2013.

11. MEERS E.F., TACK M., VERLOO M.G. Degradability of ethylenediaminedisuccinic acid (EDDS) in metal contaminated soils: implications for its use soil remediation. Chemosphere. 70 (3), 358, 2008.

12. GHOLIKANDI G.B., KARAMI S., SADABAD H.R., MASIHI H. Heavy metals removal from waste-activated sludge employing Fered-Fenton electrochemical advanced oxidation technology with the aim of agricultural land application. International Conference on Recycling and Reuse. 2016.

13. ZHU Y., ZENG G., ZHANG P., ZHANG C., REN M., ZHANG J., CHEN M. Feasibility of bioleaching combined with Fenton-like reaction to remove heavy metals from sewage sludge. Bioresource Technology. 142C (4), 530, 2013.

14. VAN GINKEL C.G., GEERTS R. Biodegradation of N, Nbis (carboxymethyl)-L-glutamate and its utilization as sole source of carbon, nitrogen, and energy by a Rhizobium radiobacter strain in seawater. Toxicological and Environmental Chemistry. 98 (1), 26, 2016.

15. HU Z.S., MO C.S., DAI Z.Y., HU J.Z., QIN L.M. Leaching Chromium from Soil Using GLDA as Eluting Agent. Southwest China Journal of Agricultural Sciences. 2422, 2016.

16. DEURZEN V., JOHANNA M.P., EUSER H., MOLL R.J., MONTEILLET H.J.M. Detergent Composition Comprising Glutamic-N, N-Diacetate, Water And Bleaching Agent. European Patent EP2794836. 2014.

17. BEGUM Z.A., RAHMAN I.M.M., TATE Y., SAWAI H., MAKI T., Hasegawa H. Remediation of toxic metal contaminated soil by washing with biodegradable aminopolycarboxylate chelants. Chemosphere. 87 (10), 1161, 2012.

18. WU Q., CUI Y.R., LI Q., SUN J. Effective removal of heavy metals from industrial sludge with the aid of a biodegradable chelating ligand GLDA. Journal of Hazardous Materials. 283, 748, 2015.

19. WANG G.Y., ZHANG S.R., LI T., LI Y. Heavy metal removal by GLDA washing: Optimization, redistribution, recycling, and changes in soil fertility. Science of the Total Environment. 569-570, 557, 2016.

20. GUNST R.F. Response Surface Methodology: Process and Product Optimization Using Designed Experiments. Technometrics. 38 (3), 284, 1996.

21. YILDIZ O., BULUT B. Optimization of Gluten-Free Tulumba Dessert Formulation Including Corn Flour: Response Surface Methodology Approach. Polish Journal of Food and Nutrition Sciences. 67 (1), 25, 2017.

22. ALVAREZ E.A., MOCHON M.C., JIMENEZ SANCHEZ J.C., TERNERO RODRIGUEZ M. Heavy metal extractable forms in sludge from wastewater treatment plants. Chemosphere. 47 (7), 765, 2002

23. LU G., LIU H., HU H.Y., ZHANG Q., YI L.L., YAO H. Fate of heavy metals in $\mathrm{CaO}$-conditioned sludge gasification. CIESC Journal. 2016.

24. LI S., ZHANG Z.L., XIONG C.G., WANG F.Q., WU S.X. Study on Removal of Heavy Metals from Municipal Sludge by Using Complexes of Citric Acid and Aspartic Acid. Industrial Safety and Environmental Protection. 2014.

25. DENG X., LI J.M., ZENG H.J., CHEN J.Y., ZHAO J.F. Research on Computation Methods of AHP Wight Vector and Its Applications. Mathematics in Practice and Theory. 2012.
26. KANG, H., LI X.X., WANG J.J., ZHANG J. Evaluating Ecological Vulnerability Using the GIS and Analytic Hierarchy Process (AHP) Method in Yan'an, China. Polish Journal of Environmental Studies. 25 (2), 2016.

27. ARAIN M.B., KAZI T.G., JAMALI M.K., JALBANI N., AFRIDI H.I., BAIG J.A. Speciation of heavy metals in sediment by conventional, ultrasound and microwave assisted single extraction methods: A comparison with modified sequential extraction procedure. Journal of Hazardous Materials. 154 (1-3), 998, 2008.

28. RAHMAN I.M.M., BEGUM Z.A., SAWAI H., OGINO M., FURUSHO Y., MIZUTANI S., HASEGAWA H. ChelantAssisted Depollution of Metal-Contaminated Fe-Coated Sands and Subsequent Recovery of the Chemicals Using Solid-Phase Extraction Systems. Water, Air and Soil Pollution. 226 (3), 1, 2015.

29. WU Q., CUI Y.R., TANG X.X., YANG H.J., SUN J.H. Extraction of Heavy Metals from Sludge Using Biodegradable Chelating Agent N,N-bis(carboxymethyl) Glutamic Acid Tetrasodium. Environmental Science. 36 (5), 1733, 2015.

30. MAJID A., PAKSERESHT M.A. Cadmium adsorption on modified chitosan-coated bentonite: batch experimental studies. Journal of Chemical Technology and Biotechnology. 88 (4), 572, 2013.

31. WU Y.Y., ZHOU S.Q., QIN F.H., LAI Y.L., PENG H.P. Optimization of Fenton process for biorecalcitrant concentrated leachate of reverse osmosis (RO) by response surface methodological analysis. Chinese Journal of Environmental Engineering. 4 (11), 2494, 2010.

32. BINGOL D., TEKIN N., ALKAN M. Brilliant Yellow dye adsorption onto sepiolite using a full factorial design. Applied Clay Science. 50 (3), 315, 2010.

33. BASHIR M.J.K., AZIZ H.A., YUSOFF M.S., ADLAN M.N. Application of response surface methodology (RSM) for optimization of ammoniacal nitrogen removal from semi-aerobic landfill leachate using ion exchange resin. Desalination. 254 (1-3), 154, 2010.

34. WANG L., YUE L., WANG K., LUO X. Optimization of electrochemical oxidation of dye wastewater using response surface methodology. Chinese Journal of Environmental Engineering. 8 (3), 990, 2014.

35. MURALIDHAR R.V., CHIRUMAMILA R.R., MARCHANT R., NIGAM P. A response surface approach for the comparison of lipase production by Canida cylindracea using two different carbon sources. Biochemical Engineering Journal. 9 (1), 17, 2001.

36. NAOUM C., FATTA D., HARALAMBOUS K.J., LOIZIDOU M. Removal of heavy metals from sewage sludge by acid treatment. Journal of Environmental Science \& Health Part A Toxic/hazardous Substances \& Environmental Engineering. $36(5), 873,2001$

37. LI Y.S., HU X.J., SONG X.Y., HOU Y.X., CHEN H.L., YANG J.S. Remediation of Soil Co-contaminated with Heavy Metals by Washing with Citric Acid:Batch Experiment and Extraction Mechanism. Journal of Shenyang University. 2012.

38. MULLIGAN C.N., YONG R.N., GIBBS B.F. Heavy metal removal from sediments by biosurfactants. Journal of Hazardous Materials. 85 (1-2), 111, 2001.

39. TANG H., SHA J.P., OUYANG L., ZHONG D., LIU G.Z. Persulfate activated by $\mathrm{Fe}(\mathrm{II})$ for oxidation and disintegration of excess sludge. CIESC Journal. 66 (2), 785, 2015. 